\title{
A Review of Transport and Urban Air Pollution in Pakistan
}

\author{
SYED ZAFAR ILYAS \\ Group of Renewable Energy and Environment, Department of Environmental Sciences, University of Balochistan, Quetta, Pakistan \\ E-mail: $\underline{\text { zzilyas@yahoo.com }}$
}

\begin{abstract}
Nowadays air over major cities throughout the world has become over burdened with gases produced by automobiles. The death rate due to automobiles pollution is increasing rapidly in the metropolitan areas. With passage of time people realized that polluted air had serious effects on their health, climate and economics. Weather and climate have the integrated impact on human activities which are resulting in worldwide concentration of the particulate of environmental pollution viz. chloroflorocarbons (CFCs), carbon dioxide, methane, nitrogen oxide, lead and several other dust and gaseous particles. The rapid growth in motor vehicle activity in Pakistan and other rapidly industrializing low-income countries is contributing to high levels of urban air pollution, among other adverse socioeconomic, environmental, health, and welfare impacts. This paper first discusses the local, regional, and global impacts associated with air pollutant emissions resulting from motor vehicle activity, and the technological, behavioral, and institutional factors that have contributed to these emissions, in Pakistan. The paper then discusses some implementation issues related to various policy measures that have been undertaken, and the challenges of the policy context. Finally, the paper presents insights and lessons based on the recent Pakistan experience, for better understanding and more effectively addressing the transport air pollution problem in Pakistan and similar countries, in a way that is sensitive to their needs, capabilities, and constraints. @JASEM
\end{abstract}

The continuous and rapid growth in population (Khan, 1986 and Syed, 2005), urbanization, industrialization and transportation (Zaman, 1985) in the city of Quetta in recent years has caused tremendous damage to the environment. The most likely major sources of atmospheric lead pollution in the city are traffic emission and industrial (Quinn, 1985). Iron mill (these use scrap iron from ships which is coated with lead), municipal wastes, contaminated food and the use of insecticides. Other sources include lead smelters, paints, solder, water pipes, storage batteries cause adverse effects and typesetting (Hutton and Symon, 1986). Air pollution has been consistently linked with substantial burdens of ill-health in developed and developing countries, with the bulk of research focused on urban outdoor (ambient) air pollution. With the rapid increase in vehicular and other pollution sources in urban areas of developing countries, and burgeoning numbers of epidemiological studies in developed countries showing effects as what used to be considered low levels, outdoor sources have remained the center of most air pollution research worldwide. Indeed, the first estimate of the global burden of disease from air pollution only addressed outdoor air pollution (Hong 1995).Motor vehicle activity has been growing rapidly in Asia, owing to rapid growth in urbanization and per capita incomes and to the vehicle production moving there, as OECD markets become saturated. Over the last three decades, motor vehicle numbers have been doubling every 10 or fewer years in many Asian countries, as against a $2 \%-5 \%$ annual growth rate in Canada, the United States, the United Kingdom, and Japan (Faiz and others 1992, Walsh 1994). Table - 1 shows the rapid growth in motor vehicles in Pakistan since the 1980s. As in many other Asian countries, motor vehicle activity has been largely concentrated in the major cities and characterized by a predominance of motorized two-wheeled (M2W) vehicles, which provide affordable mobility to millions with few other attractive options (Faiz and others 1992, Sathaye and others 1994). M2W vehicles have been the most rapidly growing vehicle type in Pakistan and represent around two-thirds of motor vehicles nationally (Table 1). Pakistan has one of the largest populations of this vehicle type. Both of these characteristics have had important implications for the high levels of health and welfare effects due to urban air pollution from transport, which is the focus of this article. Four major cities of Pakistan, including the Karachi capital of Sindh province, account for about $15 \%$ of the national motor vehicle fleet. But Karachi alone, accounts for around $6 \%$ of the nations motor vehicles (Automobile Manufacturers Association, 2005). While Karachi population has grown at around $6 \%$ per annum over the last three decades, motor vehicles grew $40 \%$ per annum in the 1980s and 1990s and decreases 50\% per annum during the 2000s. While motor vehicle numbers are no longer increasing at the same pace, they are still growing at around $7 \%$ per annum ( UN Population Division 2002, Ministry of Excise and Taxation, 2005).

Urban Air Pollution in Pakistan: The rapid growth in motor vehicle activity in cities of Pakistan has brought in its wake a range of serious socioeconomic, environmental, health, and welfare impacts. Of these impacts, those resulting from urban air pollution, due 
to emissions from motor vehicles among other sources, have been the focus of considerable public concern and policy attention. In Delhi, for example, air quality has been poor since the late 1980s. Surveys in the mid-1990s showed 24-hr average suspended particulate levels exceeding World Health Organization (WHO) guideline limits almost daily, with peak levels as high as 6-10 times the limit at many sites. Daily average sulfur dioxide and nitrogen dioxide levels exceeded WHO limits on several days annually, at several sites. Ozone has not been monitored regularly, but limited studies in the 1990s showed that short-term WHO limits were exceeded at some locations (Environment Protection Agency Pakistan, 2004). Table -2 contains recent data that show that 24-hr particulate limits continue to be

Table 1. Motor vehicle growth in Pakistan, 1975-2005

\begin{tabular}{|c|c|c|c|c|c|c|}
\hline \multicolumn{7}{|c|}{ Motor vehicle numbers, millions } \\
\hline Year & Trucks & Buses & $\begin{array}{l}\text { Cars, } \\
\text { jeeps, } \\
\text { taxis }\end{array}$ & $\begin{array}{l}\text { M2W } \\
\text { vehicles }\end{array}$ & Others & $\begin{array}{l}\text { Total } \\
\text { motor } \\
\text { vehicles }\end{array}$ \\
\hline 1975 & 0.220 & 0.05 & 0.280 & 0.05 & 0.110 & 0.71 \\
\hline 1985 & 0.600 & 0.16 & 0.86 & 0.28 & 0.192 & 2.092 \\
\hline 1995 & 3.50 & 1.32 & 3.60 & 6.3 & 1.200 & 15.92 \\
\hline 2005 & 4.00 & 2.10 & 8.29 & 20.50 & 2.700 & 37.59 \\
\hline \multicolumn{7}{|c|}{ Annual growth rate, $\%$} \\
\hline \multicolumn{3}{|c|}{ All motor vehicles } & \multicolumn{4}{|c|}{ M2W vehicles } \\
\hline \multicolumn{2}{|c|}{$1975-1985$} & 39.46 & \multicolumn{2}{|l|}{66} & & \\
\hline \multicolumn{2}{|c|}{$1985-1995$} & 86.09 & \multicolumn{2}{|l|}{20.71} & & \\
\hline \multicolumn{2}{|c|}{$1995-2005$} & 61 & \multicolumn{2}{|l|}{693.33} & & \\
\hline \multicolumn{7}{|c|}{$\begin{array}{l}\text { "Others" includes tractors, trailers, M3W vehicles, and } \\
\text { miscellaneous vehicles }\end{array}$} \\
\hline
\end{tabular}

exceeded even in residential areas. Such high air pollution levels occur in Karachi and other major cities of Pakistan, because of the concentration of motor vehicular and other energy-consuming activities in these cities and the high pollution intensity of these activities. And because of the large populations in these cities, significant exposures and health impacts result. It was reported in 2001 that 70 million people in Karachi, and $40 \%$ of its children, suffered from respiratory diseases (Syed Zafar Ilyas, 2005 ). The rapid growth in motor vehicle and other energy-intensive activities in Pakistan is important not only because of their locally harmful air pollution effects, but also because of their regional and global impacts. Acidification and ground-level ozone effects are increasing rapidly in Asia. Even low ozone levels can seriously diminish crop yields, but ozone appears to affect tropical crops more severely than US and European ones. While damage is estimated to be $10 \%$ in the United States (except for sensitive crops), it could be $40 \%$ for wheat, soybean, rice, and groundnut in countries like Pakistan, with profound implications for food security (Roychowdhury 1997).

At the global level, the rapid growth in motor vehicle activity has serious energy security and climate change implications. Transport already consumes nearly half of the worlds oil. Energy consumption and carbon dioxide emissions due to transport grew by about a third in just one decade since the 1990s, with nearly half of this increase coming from the low-income countries (Gru"bler 1994). In Pakistan, petroleum product consumption, half of which is accounted for by transport, has very nearly doubled in just the last decade. The gap between local oil production and demand has been rising rapidly, and it is expected that $60 \%$ of Pakistan oil requirement will have to be imported in 2006 ( Economic Division, Govt. Of Pakistan, 2005).

Table - 2 : Twenty - four - hours average air pollutant levels in Karachi, 2001 and $2005\left(\mu \mathrm{g} / \mathrm{m}^{3}\right)$

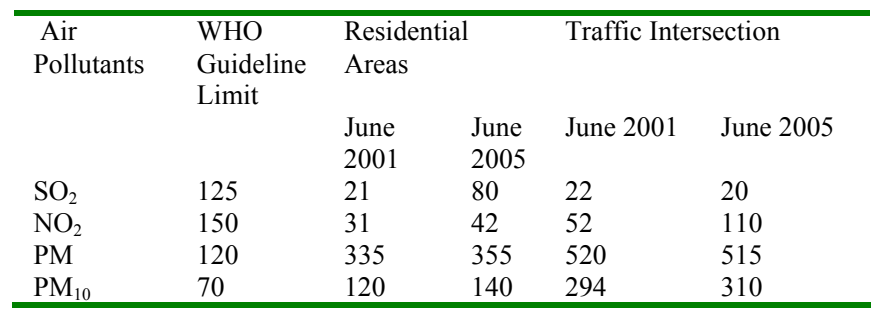

The Role of Transport in Urban Air Pollution: Pakistan emissions inventories are not reliable; for example, transport emission inventories have tended to account only for vehicle exhaust, not for other vehicle and transport system sources, and have employed emission factors that do not adequately represent actual vehicle populations or in-use conditions. Besides, there are discrepancies between inventories generated by different agencies (Syed Zafar Ilyas, 2005). Notwithstanding these issues, the available data show, in Karachi, for example, that motor vehicles are predominant in terms of carbon monoxide, hydrocarbons, and nitrogen oxides. And although their share of particulate and sulfur dioxide 
emissions is considerably lower than that of other sources (Syed Zafar Ilyas, 2005), their contribution to these emissions and, more generally, the contribution of urban transport to air pollution are likely growing in cities of Pakistan, given the rapidly growing motor vehicle activity. The bulk of transport generated particulates is $\mathrm{PM}_{10}$, which is strongly linked with morbidities and mortalities associated with respiratory and cardiovascular diseases. Table -2 compares 24-hour average air pollutant levels at the traffic intersection, where emissions are predominantly transport generated, with those in residential areas.

While more recent model vehicles have been entering the market with economic liberalization since the 1990s. Motor vehicle activity in Pakistan has therefore been characterized by high pollution intensities. The vast majority of M2W vehicles, which form the bulk of Pakistan motor vehicle fleet, and for-hire motorized three-wheeled (M3W) vehicles have until recently been powered by highly polluting two-stroke engines. Tests conducted in the early 1990s showed that these vehicles, which typically carry one to four persons, produced higher carbon monoxide and hydrocarbon and one-fourth the particulate emissions per kilometer relative to buses, which are themselves heavy polluters, especially in terms of particulates (Syed Zafar Ilyas, 2005).

In addition to their high pollution levels, M2W vehicles are used intensively and, consequently, have accounted for significant shares of transport emissions. In Karachi in the start 2000, for example, these vehicles accounted for $60 \%$ of vehicle- kilometers (but as little as $15 \%$ of passengerkilometers) in motorized passenger vehicles and approximately $32 \%-52 \%$ of exhaust carbon monoxide, hydrocarbon, and particulate emissions from all motor vehicle activity. Their contribution was marginal only in terms of nitrogen oxides and sulfur dioxide, for which buses and other diesel vehicles were primarily responsible (Syed Zafar Ilyas, 2005). Thus, M2W and M3W vehicles have represented a serious problem in terms of emissions per passenger-kilometer. Additionally, M2W vehicles alone consume around half of all gasoline nationally.

Fuel and lubricating oil quality have also contributed significantly to transport air pollution. Until the 1990s, when significant improvements in fuel quality began to be implemented, lead content was excessively high (Table 3). Lead in gasoline has been a serious public health concern globally, because it is released predominantly in the form of $\mathrm{PM}_{10}$, and even low lead levels can cause neurological effects in children, which can persist even after exposure ends ( Faiz et al, 1992). Benzene, a known carcinogen implicated in adult leukemia and lung cancer, and for which the WHO specifies no safe limit in air (Faiz et al, 1992), was not controlled in Indian Pakistan until recently (Table 3).

Ambient benzene levels in Karachi in the late 2000 were an order of magnitude higher than those allowed by the European Union. Levels of sulfur, an important constituent in particulate emissions, were excessively high in Pakistan gasoline and diesel until the 1990s (Table 3), and several orders of magnitude higher than in their US and Californian counterparts at the same time (Faiz et al, 1996).

Table 3. Pakistani Fuel Quality

\begin{tabular}{|c|c|c|c|c|c|}
\hline & \multicolumn{5}{|c|}{ Gasoline } \\
\hline & 1990 & 1995 & 2000 & 2005 & Proposed \\
\hline $\begin{array}{l}\text { Lead content, } \\
\mathrm{g} / \mathrm{L} \max \end{array}$ & 0.60 & 0.16 & 0.12 & 0.13 & 0.005 \\
\hline $\begin{array}{l}\text { Sulfur, total, } \\
\% \text { by mass, max }\end{array}$ & 0.23 & $\begin{array}{l}0.20 \text { in } \\
\text { low } \\
\text { leaded } \\
\text { gasoline }\end{array}$ & $\begin{array}{l}0.20 \text { in low } \\
\text { leaded } \\
\text { gasoline }\end{array}$ & $\begin{array}{l}0.20 \text { in low } \\
\text { leaded } \\
\text { gasoline }\end{array}$ & 0.015 \\
\hline $\begin{array}{l}\text { Reid vapor pressure } \\
\text { (RVP), } \mathrm{kPa}, \max \end{array}$ & $33-65$ & $33-65$ & $32-62$ & $32-60$ & 60 \\
\hline $\begin{array}{l}\text { Benzene content, \% by } \\
\text { volume, max }\end{array}$ & ND & ND & $\begin{array}{l}\text { 1(metros) } \\
3 \text { (rest of } \\
\text { country) }\end{array}$ & $\begin{array}{l}\text { 1(metros) } \\
3 \text { (rest of } \\
\text { country) }\end{array}$ & 1 \\
\hline $\begin{array}{l}\text { Olefin content, } \% \\
\text { by volume, max }\end{array}$ & ND & ND & ND & ND & 21 \\
\hline $\begin{array}{l}\text { Aromatics content, } \% \\
\text { by volume, } \max \end{array}$ & ND & ND & ND & ND & 42 \\
\hline $\begin{array}{l}\text { Oxygen content, } \\
\% \text { by mass, max }\end{array}$ & NA & 2.1 & 2.2 & 2.2 & 2.7 \\
\hline Existent gum, & 30 & 30 & 32 & 32 & 40 \\
\hline
\end{tabular}




\begin{tabular}{|c|c|c|c|c|c|}
\hline \multirow[t]{2}{*}{$\begin{array}{l}\mathrm{g} / \mathrm{m}^{3}, \max \\
\text { Engine intake } \\
\text { system Cleanliness }\end{array}$} & ND & ND & \multicolumn{3}{|c|}{$\begin{array}{l}\text { MFA required; tests specified; limits } \\
\text { specified in } 1997\end{array}$} \\
\hline & \multicolumn{2}{|c|}{ Diesel } & 2000 & 2005 & Proposed \\
\hline $\begin{array}{l}\text { Sulfur, total, } \% \\
\text { by mass, } \max \end{array}$ & 0.8 & 0.8 & 0.24 & $\begin{array}{l}0.04 \text { in } \\
\text { metros }\end{array}$ & 0.035 \\
\hline \multicolumn{6}{|c|}{$\begin{array}{l}\text { kPa-kilopascals; MFA-multifunctional additive; NA-not applicable; ND—no Data; } \\
\text { Metros - Karachi, Lahore, Peshawar, and Quetta. Unless otherwise specified, the years } \\
\text { indicate when changes in fuel quality were implemented countrywide. The changes may } \\
\text { have been implemented in notified areas previously (for example, gasoline with } 0.16 \text { and } \\
0.12 \mathrm{~g} / \mathrm{L} \text { lead content was implemented in the above four cities in } 1995 \text { and } 1997, \\
\text { respectively). See the sources for details regarding test procedures and other details. }\end{array}$} \\
\hline
\end{tabular}

Another important issue in the Pakistan context is that of gasoline evaporative emissions. There are no evaporative controls on the fuel distribution system, or on vehicles except cars produced from 1997 (Ministry of Environment, 1997). Pakistani gasolines have a high volatility, and the vast majority of gasoline vehicles are carbureted, not fuel-injected. These facts, along with Pakistan high ambient temperatures, heighten the potential for evaporative emissions rich in reactive hydrocarbons, which participate in the formation of ground-level ozone.

The effects of vehicle technology and fuel quality have been exacerbated by in-use operating conditions. Congestion has increased rapidly in cities of Pakistan, because of inadequate road infrastructure, modal separation, transport system management and traffic control. In Karachi, for example, the average speed for motorized passenger vehicles ranged from 25 to $50 \mathrm{~km} / \mathrm{hr}$ in the $1990 \mathrm{~s}$. Besides causing time and productivity losses, congestion can increase fuel consumption, and carbon monoxide and hydrocarbon emissions per vehicle-kilometer, by $200 \%$ or more (Faiz et al, 1992).

Several studies worldwide have shown that maintenance is a significant factor in vehicular emissions. Particulates can increase 10-fold in poorly maintained two-stroke M2W and M3W vehicles using poor-quality lubricating oil and by 20 times in diesels with damaged fuel injection systems (Faiz et al, 1996, Shah and Nagpal 1997). One would expect good vehicle maintenance, given the low labor and high fuel costs in Pakistan. However, many vehicle users maintain their vehicles themselves, or use the services of local mechanics, and only when absolutely unavoidable. Further, spurious spares are commonly used, because of expensive quality spares, partly on account of high sales taxes. Poor vehicle maintenance is also enabled by largely ineffective monitoring and enforcement. Vehicle emission inspection regimes, such as in Karachi, have combined a decentralized test-repair system and noload testing, which is technically flawed, open to corruption, and burdensome for users, who have circumvented or subverted the testing process.

Fuel and lubricating oil adulteration has also been an important contributory factor. M3W vehicle operators, who typically do not own their vehicles, commonly adulterate gasoline with as much as $25 \%$ kerosene and even solvents. To guard against the resulting wear and tear, they mix as much as $15 \%$ of lubricating oil, the principal source of particulates in two-stroke engines. This adulteration has been enabled principally by the fact that kerosene, which is the poor persons cooking fuel, has been heavily subsidized and is $10-15$ times cheaper than gasoline. Diesel is adulterated with kerosene also, though the diesel-kerosene price differential is lower than for gasoline-kerosene. Diesel is of concern because it accounts for a significant share of petroleum product consumption and imports, and diesel exhaust contains particulates that are predominantly in the fine particulate range, and many toxic air contaminants.

Vehicle Emission Control Policies and Issues: A policy measures have been undertaken over the last decade to address motor vehicle emissions, in response to the deteriorating air pollution in major cities of Pakistan. Some key measures are discussed, along with some related implementation issues.

Motor vehicle emission standards have been made progressively more stringent since the 1990s. As for M2W vehicles, which have been characterized by high emission levels, exhaust emission standards for the year 2000 are the strictest in the world. With rapidly deteriorating urban air quality, fuel quality improvements have been implemented in countrywide, since the 1990s (Table 3). Further improvements in both vehicle emission and fuel quality standards are contemplated over the next few years. 
The Pakistan vehicle emission standards have become increasingly stringent, in-use vehicle emissions on even recent model vehicles could be considerably higher than the standards would indicate, because of the various factors discussed earlier. Indeed, many in-use vehicles have been found to fail in use emission tests, lenient as they are. And though some improvements have been made to the regime for in-use vehicle emissions monitoring and control, by way of computerization and surveillance, the system remains substantially the same (Roychowdhury 2002).

Although Pakistan transport fuels are still inferior to those presently available and that are likely to come on-stream in Europe and the United States (World Bank 2003), the above improvements represent a very significant advance. But the full potential of these improvements may not have been realized. It is likely that the effectiveness of catalytic converters on many new vehicles suffered, on account of misfueling because of the lack of widespread availability of unleaded fuel outside the metropolitan centers, smuggled fuel from Iran and Iraq , particularly in the early phases of implementation. Secondly, adulteration has very likely neutralized improvements in fuel quality. The retail prices of kerosene and diesel were increased significantly in 2000, after being debated for several years. In the case of kerosene, this increase was as much as around $100 \%$. But while removing kerosene subsidies might reduce adulteration of transport fuels and help mitigate transport emissions, it is likely that kerosene might become less affordable for the large number of low income households that use it as a cooking, lighting fuel even in urban areas and potentially produce trade-offs in terms of indoor air pollution, as they are forced to revert to traditional fuels.

Many new engine technologies coming on-stream in response to increasingly stringent emission standards are highly sensitive to fuel and maintenance quality. In the case of catalytic converters, stable spark ignition would be required for effective functioning, but spark plugs could be susceptible to malfunctioning in $\mathrm{M} 2 \mathrm{~W}$ and $\mathrm{M} 3 \mathrm{~W}$ vehicles, because of dirty operating conditions and poor air filtration and maintenance. Additionally, converters need to withstand a high degree of vibration on these vehicles (Faiz et al, 1996). Frequent replacement of the catalyst would be expensive and burdensome, for both vehicle users and manufacturers, who are liable in case of failure in service. On catalytically controlled vehicles, effective converter functioning depends on precise air-fuel ratio control provided by electronic fuel injection, but this technology has run into problems of clogged injectors, because of inadequate deposit control in in-use gasoline. Similarly, the effectiveness and durability of fourstroke engines on M2W vehicles could be compromised, because although fuel quality has been improved in terms of engine intake system cleanliness and refiners are required to use multifunctional additives for this purpose (Table -3 ), in-use fuels fall considerably short of specifications in this regard (Iyer, 2002).

To maintain octane rating to compensate for lead removal and benzene reduction in 2000, methyl tertiary butyl ether (MTBE) has been added to gasoline. And since 2004, ethanol is being added to gasoline in several provinces of Pakistan (Government of Pakistan, 2004). In vehicles without catalytic converters, the addition of oxygenates can cause increased emissions of reactive aldehydes and nitrogen oxides, thus potentially aggravating the ozone problem (Faiz et al, 1992, Humberto Bravo et al, 1991).

Several policy measures have been targeted exclusively in Karachi, reflecting the policy concern regarding the air pollution situation in the capital of sindh province. These measures, pursuant to Supreme Court rulings in May 2006, include supply of metered lubricating oil premixed with gasoline and a ban on the sale of loose lubricating oil, for motorized vehicles powered by two-stroke engines, to minimize adulteration of lubricating oil and ensure correct oilfuel ratios; and the conversion of $\mathrm{M} 3 \mathrm{~W}$ vehicles, taxis, and buses to compressed natural gas $(\mathrm{CNG})$.

The implementation of CNG in Karachi must count as a significant achievement by any standards. It is perhaps the first instance, after Brazil and India, of alternative transport fuels being implemented on such a large scale in a low-income country. And Delhi is certainly the only city in the world to have converted its entire public vehicle fleet to run on an alternative fuel. However, concerns have been raised about the cost-effectiveness of $\mathrm{CNG}$ conversion, technology reliability, performance, and serviceability and the possibility of bus fleet reduction on account of the inability to afford conversion to $\mathrm{CNG}$ on the part of many bus operators and, consequently, reduced access to affordable transit service and increased personal motor vehicle use.

Finally, road infrastructure measures, in the form of limited access expressways and grade-separated intersections, to alleviate traffic congestion and reduce per-vehicle emissions, are being implemented 
in various Pakistani cities. Such policies could result in the displacement of the urban poor, given the high density and poverty levels in cities of Pakistan, and further compromise access and mobility for the millions who have no recourse but to walk or use nonmotorized modes.

The Policy Context and its Challenges: A multitude of government agencies and private actors at the national, regional, and local levels is responsible for the various roles and functions that have important implications for air pollution from urban transportthe development and implementation of vehicle emission and fuel and oil quality standards; vehicle licensing, registration, and inspection; certification and licensing of fuel dispensing and service stations to test in-use vehicle emissions and repair noncomplying vehicles; fuel adulteration control; transport system management and traffic control; transportation planning, road construction and maintenance; and land use. In the case of many of these important functions, agency roles and responsibilities are fragmented, overlapping, and conflicting. In addition to this jurisdictional complexity, interactions between the various agencies and actors have been characterized, at least until recently, by conflict. Also, an important barrier to rapid and effective action has been the fact that many of the key actors, being government agencies, are difficult to regulate effectively.

Addressing transport air pollution is challenging enough because, as in other contexts, this problem in Pakistan is complex and multidimensional; it involves a variety of pollutants from a range of motor vehicles and other sources, the daily travel and vehicle purchasing, operation, and maintenance choices of millions of vehicle users, and a multitude of actors and affected groups. This challenge is made more daunting in the Pakistan case, because of the restricted financial, technological, and administrative resources for effectively fulfilling the above important functions.

Implications for Policy-Making and Implementation: Transport air pollution is an issue that is becoming increasingly important in urban areas, not only in Pakistan but also in many other low-income countries, as motor vehicle activity grows rapidly. What insights and lessons can one draw from the recent Pakistan experience, for better understanding and more effectively addressing this problem in Pakistan and similar contexts? While transport air pollution inevitably involves technological issues, it is also influenced by vehicle user choices and by the institutional setting that in part influences those choices. As we have seen, poor in-use fuel and oil quality is a result of technology constraints, but is also due to adulteration resulting from relative fuel pricing and ineffective enforcement. Poor vehicle maintenance is a result of limited affordability on the part of vehicle users, but is also due to the burdensome and ineffective in-use emissions monitoring and control regime and high spare parts taxes. Such interactions between technological, political-institutional, and human behavioral factors need to be carefully considered. Emission control policies can have distributional consequences, even as they improve conditions that affect the poor the most. Policies targeted at motor vehicle emissions have transport system impacts beyond air pollution, and cost and welfare impacts for different actors and groups, as in the case of road infrastructure measures. And as in the case of kerosene subsidies, policies directed at transport emissions can generate impacts and trade-offs in sectors other than transport. It is therefore important to minimize adverse policy impacts for vehicle users, particularly those with low incomes, and for nonusers, many of whom are poor and enjoy none of the benefits of motor vehicles, while involuntarily bearing the brunt of their impacts. More generally, it would be desirable to consider system- wide policy impacts from the perspective of different actors and groups, who are differentially affected by policies, to reconcile trade-offs and conflicts.

Policy robustness and cost-effectiveness are important in any context, but particularly so in countries like Pakistan, given their resource constraints and the significant proportion of vehicle users with low incomes. It is therefore imperative that policy-making and implementation be acutely sensitive to contextual capabilities and constraints. As demonstrated by our discussion of the implications of harsh operating conditions and ineffective monitoring and enforcement for catalytic converter effectiveness, it would be desirable to explicitly consider implementation issues and in-use realities as an integral part of policy analysis, rather than assuming that policies will be implemented in a friction-free world. It would also be desirable to explicitly consider how the vehicle industry and vehicle users would be affected by and respond to policies. Users would find costly emission control technologies and policies acceptable only if features such as fuel economy, trouble-free operation, easy and inexpensive serviceability, long service life, and resale value were not compromised. Considering inuse realities, implementation issues and vehicle user perspectives will enable institutional mechanisms to be put in place to anticipate and address problems 
and to support policies well in advance of their introduction. This approach would also enable robust policies that are insensitive to poor operating conditions and that minimize reliance on expensive institutional support mechanisms.

As noted, financial incentives were applied successfully to encourage speedy conversion of M3W vehicles to CNG in Karachi. This demonstrates the importance of coordinating technological, regulatory, and economic policies. And since these policies are determined by or affect multiple actorsgovernments at various levels, vehicle and fuel manufacturers and retailers, the vehicle servicing industry, and vehicle users - all of these actors should ideally be involved in policy development and implementation. Additionally, agencies responsible

for public health, air quality and emissions monitoring, land use and transport planning, transport system management, traffic control, and vehicle registration, inspection, and maintenance should be included, in order to more effectively coordinate action. But beyond such coordination, it would be desirable to explore collaborative approaches to engage stakeholders and affected groups on an ongoing basis, to integrate their diverse interests and concerns, and design policy packages that represent mutually beneficial compromises and that are both effective and equitable.

Some applications of these general principles follow. Because of the importance of cost-effectiveness, it would be highly desirable to develop a comprehensive emissions inventory that accounts for all transport system sources, and real-life vehicle operation, maintenance, and disposal conditions, in order to target control action at the most important sources and factors contributing to pollutants of concern. Given resource constraints, and the need for urgent action, there would be great value in estimating an emissions inventory that minimized specification errors, as above, while accounting for measurement errors by employing ranges for various variables, based on the best available information, and informed expert judgments. In the interests of long-term effectiveness, it would be desirable for emission control technologies, many of which can be complex, costly, and sensitive to maintenance quality, to be designed carefully before being implemented, for the vehicle servicing industry to be adequately prepared to handle these technologies well in advance of introduction, and for widespread availability of moderately priced quality spares to be ensured. While institutional mechanisms such as effective inspection and maintenance regimes to support vehicle technologies and appropriate spare parts taxation need to be put in place, it would be desirable to implement policies that target critical factors and pollutants and deliver results rapidly, such as fuel and oil quality improvements, stop smuggled fuel and oil (from Iran and Iraq) and metered fuel-oil mixtures on two strokes. Such measures would also be "fit and forget" in nature, which would enhance vehicle user acceptability.

With specific reference to M2W vehicles, public policy should address their air pollution impacts, while not adversely compromising the considerable benefits these vehicles afford many. Users would be willing to reduce their use of these vehicles only if these benefits were preserved by other means, such as accessible, frequent, convenient, and affordable public transit. If vehicle scrap page is contemplated, it is best that it is based on emissions performance, rather than on a fixed number of years, to serve as an incentive to quality maintenance, while preserving vehicle value. Such a scheme would of course require an effective in-use emissions monitoring and control regime. A system to buy back old vehicles and sell them after reconditioning in the hinterland would make emissions performance-based scrap page more attractive and promote timely vehicle disposal and rapid penetration of improved technologies. Offering credits to vehicle manufacturers would serve as an incentive to implement such a scheme.

Technological measures such as those related to vehicle and fuel technologies, highway capacity, and transport system management have an important role in addressing air pollution and other transport impacts, but can involve considerable financial and administrative resources. While technological measures can be neutralized by increasing motor vehicle activity and congestion even without resource constraints, resources in Pakistan are far from adequate to accommodate even present levels of motor vehicle activity, let alone future growth. In this context, even after conversion of the public vehicle fleet to $\mathrm{CNG}$, and a host of other policy measures as discussed, there has been no significant improvement in Karachi, particularly in terms of particulates (Table 2). Motor vehicle growth is as rapid, and air pollution levels are at least as high, in many other cities of Pakistan as in Karachi. These cities have nowhere near the resources that Karachi does, and approaches like CNG would be difficult to replicate in them, owing to prohibitively high cost. Lastly, the implications of rapid growth in motor vehicle and other energy consuming activities in countries like Pakistan for regional acidification, climate change, 
and energy security will likely become more serious with time.

As motor vehicle activity continues to increase rapidly in the cities of Pakistan, the challenge will be, how to meet growing mobility needs, while minimizing local, regional, and global environmental impacts. Given that providing for motorization and mitigating its impacts can involve considerable resources, in a context of resource

constraints and a multiplicity of urgent demands, and given also that the vast majority of city dwellers are poor and benefit little from motorization, it would be desirable for countries such as Pakistan to develop transport systems that take into consideration their unique needs and priorities, as well as their capabilities and constraints, to achieve low-cost, fail safe, and robust policy outcomes, and to accord primacy to minimizing personal motor vehicle activity, by providing attractive alternatives such as extensive, reliable, and convenient public transit and facilities for safe walking and cycling.

Acknowledgment: I am grateful to the Prof . Dr. T. Nejat Veziroglu, Director, Clean Energy Institute,Mechanical Engineering University of Miami ,Coral Gables,Florida, USA.

\section{REFERENCES}

A. Zaman. "Pakistan economic survey 1984-85, Ministry of Finance”, Islamabad, Pakistan. 1985

Badami, M. G. 2001. A multiple-objectives approach to address motorized two-wheeled vehicle emissions in Delhi, India. Unpublished Ph.D. dissertation. University of British Columbia, Vancouver, $321 \mathrm{pp}$.

Environment Protection Agency, Govt. Of Pakistan, 2004.

Faiz, A., C. Weaver, K. Sinha, M. Walsh, and J. Carbajo. 1992. Air pollution from motor vehicles: issues and options for developing countries. The World Bank, Washington, DC, $280 \mathrm{pp}$.

Faiz, A., C. S. Weaver and M. P. Walsh, with S. Gautam and L.- M. Chan. 1996. Air pollution from motor vehicles: standards and technologies for controlling emissions. The World Bank, Washington, DC, 246 pp.

Gru“ bler, A. 1994. The transportation sector: growing demand and emissions. Pages 44-57 in
R. Krishnan (eds.), Growing numbers and dwindling resources. Tata Energy Research Institute, New Delhi.

Hong, C. (1995). Global Burden of Disease from Air Pollution. Geneva, World Health Organization.

Humberto Bravo, A., J. R. Torres, and E. R. Sosa. 1991. Motor vehicle pollution control in Mexico City. SAE Technical Paper No. 912426. Society of Automotive Engineers, Warrendale, PA, 6 pp.

Government of Pakistan, 2004

Iyer, N. V. 2002. Submission to Discussion Forum on Enforcing Emission Standards for In-Use Vehicles, July 11, The World Bank, Washington, DC; available at http://nweb18.worldbank. org/SAR/sa.nsf/All/2F391E72031478F6.

Kojima, M., C. Brandon, and J. Shah. 2000. Improving urban air quality in South Asia by reducing emissions from two stroke engine vehicles. The World Bank, South Asia Environment Unit, Washington, DC, 46 pp.

Kumar, R. 2002. Submission to Discussion Forum on Enforcing Emission Standards for In-Use Vehicles, July 17, The World Bank, Washington, DC; available at http://nweb18.worldbank. org/SAR/sa.nsf/All/2F391E72031478F6.

M.Ali.Khan. "A review of the atmospheric pollutants in Pakistan. The City of Lahore", In Int. Symp."Environmental pollution and toxicology", 9-11 September, 1986, HongKong, Baptist College, Kowloon, Hong Kong.

M.J. Quinn. "Factors affecting blood lead concentration in the U.K. Results of the EEC blood lead surveys", Int. J. Epidemiol., 14(1985),420-431,1979-81.

M.Hutton and C. Symon. "The quantities of cadmium, lead, mercury and arsenic entering the UK environment from human activities", Sci. Total Environ., 57, 129-150 (1986).

Ministry of Excise and Taxation, 2005

Ministry of Economic Division, 2005

Ministry of Environment, 1997

Roychowdhury, A. 1997. Ozone: the other angle. Down to Earth 6(14):20-23. 
Roychowdhury, A. 2002. Submission to Discussion Forum on Enforcing Emission Standards for InUse Vehicles, July 17, The World Bank, Washington, DC; available at http:// lnweb18.worldbank.org/SAR/sa.nsf/All/2F391E $72031478 \mathrm{~F} 6$.

Sathaye, J., S. Tyler, and N. Goldman. 1994. Transportation, fuel use and air quality in Asian cities. Energy 19(5):573-586.

Shah, J. J., and T. Nagpal. 1997. Urban air quality management strategy in Asia-Greater Mumbai report. World Bank Technical Paper No. 381. The World Bank, Washington, DC, 227 pp.

United Nations Population Division. 2002. World urbanization prospects - The 2001 revision, data tables and highlights.

UN Population Division, Department of Economic and Social Affairs, United Nations Secretariat, New York, 182 pp.
Walsh, M. P. 1994. Trends in automotive transport: implications for environmental protection, energy efficiency and sustainable development. Paper presented at the International Conference Toward Clean Transport: Fuel Efficient and Clean Motor Vehicles, Mexico City, March 2830 .

World Health Organization and United Nations Environment Programme. 1992. Urban air pollution in mega cities of the world. Blackwell Publishers, Oxford, pp. 155-164.

World Bank. 2003. Annex 3-Trends in vehicle emission standards and fuel specifications in the European Union. Draft for comment. The World Bank, Washington, DC; available at http://www.worldbank.org/cleanair/global/ documents/handbook03/handbook_annex3.pdf.

Syed Zafar Ilyas, 2005. "Environmental Simulation in Quetta, Pakistan", Unpublished, $\mathrm{PhD}$ thesis, University of Balochistan, Quetta, Pakistan, 